\section{THE ED YOUNG PERSON'S WELLBEING GUIDE - A NOVEL APPROACH TO PSYCHOSOCIAL RISK ASSESSING CHILDREN AND YOUNG PEOPLE IN THE EMERGENCY DEPARTMENT}

${ }^{1}$ Lauren Fraser, ${ }^{2}$ Ayia Al-Asadi. ${ }^{1}$ Northwick Park Hospital; ${ }^{2}$ London North West University Healthcare NHS Trust

10.1136/emj-2020-rcemabstracts.50

Aims/Objectives/Background The 2019/20 RCEM National QIP 'Care of Children in the ED' recommends use of a recognised tool (eg HEEADSSS) to psychosocial risk assess 12-17 year olds seen in the ED. Northwick Park's ED team collaborated with the Young Harrow Foundation (YHF), a local charitable organisation, to coproduce the ED Young Person's Wellbeing Guide with the aim of addressing this standard whilst also meeting the needs of ED staff and the children and young people (CYP) that we care for.

Methods/Design YHF's Change Champions, a dynamic group of local 15-25 year olds with lived experience of areas such as youth violence and mental health, worked with the ED team and fed back that they wouldn't necessarily expect (or welcome) ED staff enquiring about such personal topics (particularly if presenting with an unrelated issue) but valued access to reliable support and advice for themselves or their peers. ED staff, similarly, often felt awkward approaching such sensitive subjects with CYP if the presentation was with a seemingly unrelated complaint or when departmental pressures prohibited development of a meaningful doctor-patient rapport. The Wellbeing Guide was therefore coproduced to provide CYP with links to trusted sources of support (based on the HEEADSSS categories) as well as allowing the ED clinician to broach such conversations by asking whether any issues raised in the Guide resonated with the young person and whether further support or advice was required.

Results/Conclusions The Wellbeing Guide will be piloted, and offered to all 12-17yo's attending the ED, in the next few weeks. Using an iterative approach the document will be further developed through feedback from CYP. We are also developing a complementary document containing links to resources for parents concerned about their child. We aspire to an online version of both documents, accessible via the Trust's website, in the next few months.

\section{TIMING OF PAEDIATRIC PRESENTATION TO THE EMERGENCY DEPARTMENT DURING THE COVID-19 LOCKDOWN}

${ }^{1}$ Rachel Harwood, ${ }^{2}$ Damian Roland, ${ }^{3}$ David Patel, ${ }^{4}$ Fiona Mendes, ${ }^{5}$ Andrew Fitzsimmons, ${ }^{6}$ Niall Mullen, ${ }^{7}$ David James, ${ }^{7}$ Jane Bayreuther, ${ }^{8}$ Clare Peckham. ${ }^{1}$ Alderhey Children's Hospital; ${ }^{2}$ Leicester University and Hospitals; ${ }^{3}$ Portsmouth Hospital; ${ }^{4}$ James Paget Hospital; ${ }^{5}$ Belfast Children's Hospital; ${ }^{6}$ Sunderland Hospitals; ${ }^{7}$ Southampton Children's ED; ${ }^{8}$ Morecombe Bay Hospitals Trust

\subsection{6/emj-2020-rcemabstracts.51}

Aims/Objectives/Background Paediatric presentations to the emergency department (ED) reduced significantly during the COVID-19 lockdown. Concerns were raised that children were coming to harm as a result of delayed presentations to ED and rapid guidance was produced for parents to highlight red and amber symptoms which should prompt ED review. NHS 111 responses were also adapted for children to facilitate rapid recognition of the sick child.

The aim of this rapid surveillance project was to objectively describe the proportion of children who had a delayed presentation to ED during the COVID-19 lockdown and their need for admission.

Methods/Design Prospective anonymous data collection on children presenting to ED during periods between 20th April and 8th July 2020 in 7 trusts in England and Northern Ireland. Clinicians (doctors and advance care practitioners) were asked to feedback at the time of patient dispostion about whether

i. the parents had reported a delay in presenting to hospital

ii. the parents had experienced a delay secondary to another service provider (primary care/111)

iii. there was no delay in presentation

iv. they were uncertain as to whether there was a delay.

Data was a collected via an approved website with appropriate data goverance.

Results/Conclusions 1637 patients patient entries were recorded, the majority in May 2020 (86\%). Patient characteristics and outcomes are shown in table 1.

Diagnosis of 11 patients with delayed presentation requiring admission: sepsis, abdominal pain of unclear cause, abscess, bronchiolitis, headache, GORD, DKA, testicular torsion and viral induced wheeze.

\begin{tabular}{|c|c|c|c|c|c|c|c|c|}
\hline Age & $\mathrm{N}$ & Red Sx & Amber Sx & 111/GP input & Parental delay & GP/111 delay & $\begin{array}{l}\text { Admission to } \\
\text { PICU if delayed }\end{array}$ & $\begin{array}{l}\text { Admission to } \\
\text { ward if delayed }\end{array}$ \\
\hline 0-6 weeks & 67 & $7(10.4 \%)$ & $19(28.4 \%)$ & $23(34.3 \%)$ & $3(4.5 \%)$ & $0(0.0 \%)$ & 1 (33.3\%) & 1 (33.3\%) \\
\hline 7 weeks - 3 months & 51 & $4(7.8 \%)$ & $17(33.3 \%)$ & $50(98.0 \%)$ & $0(0.0 \%)$ & $1(2.0 \%)$ & $0(0.0 \%)$ & $0(0.0 \%)$ \\
\hline 4-6 months & 47 & 7 (14.9\%) & $11(23.4 \%)$ & $22(46.8 \%)$ & $4(8.5 \%)$ & $4(8.5 \%)$ & $0(0.0 \%)$ & $0(0.0 \%)$ \\
\hline 7-11 months & 116 & $10(8.6 \%)$ & $22(19.0 \%)$ & $50(43.1 \%)$ & $2(1.7 \%)$ & $0(0.0 \%)$ & $0(0.0 \%)$ & $0(0.0 \%)$ \\
\hline 1 year & 198 & $15(7.6 \%)$ & $43(21.7 \%)$ & $58(29.3 \%)$ & $4(2.0 \%)$ & $3(1.5 \%)$ & $0(0.0 \%)$ & $1(14.3 \%)$ \\
\hline $2-5$ years & 471 & $14(3.0 \%)$ & $98(20.8 \%)$ & $107(22.7 \%)$ & $11(2.3 \%)$ & $1(0.2 \%)$ & $1(8.3 \%)$ & $1(8.3 \%)$ \\
\hline $6-10$ years & 388 & $22(5.7 \%)$ & $112(28.9 \%)$ & $105(27.1 \%)$ & $17(4.4 \%)$ & $4(1.0 \%)$ & $0(0.0 \%)$ & $3(14.3 \%)$ \\
\hline $11-15$ years & 299 & $22(7.4 \%)$ & 64 (21.4\%) & $64(21.4 \%)$ & $12(4.0 \%)$ & $2(0.7 \%)$ & $0(0.0 \%)$ & $3(21.4 \%)$ \\
\hline Total & 1637 & $101(6.2 \%)$ & $386(23.6 \%)$ & $449(27.4 \%)$ & $53(3.2 \%)$ & $15(0.9 \%)$ & $2(2.9 \%)$ & 9 (13.2\%) \\
\hline
\end{tabular}

Sx: Signs (as per RCPCH guidance)

PICU: Paediatric Intensive Care Unit 